\title{
Maneirismo Musical: uma reflexão sobre a proximidade entre a estética do Maneirismo e a arte musical
}

\author{
Rafael Luis Garbuio \\ Universidade Federal da Bahia | Orcid: 0000-0003-4259-2238
}

\begin{abstract}
Resumo
O Maneirismo artístico é a reclassificação estética que se faz de um segmento das obras artísticas elaboradas nas décadas finais do século XVI, quando a sociedade europeia passou por profundas transformaçóes que ecoaram na linguagem artística. No repertório musical do período encontramos um seleto grupo de madrigalistas cujas obras se aproximam das características do Maneirismo. Tal aproximação oferece ferramentas relevantes para que se aprofunde o seu entendimento. Este artigo realizou uma reflexão sobre a estética do Maneirismo e sua aplicação no repertório musical reforçando a comprovação de sua existência e sua relevância na história da música.
\end{abstract}

Palavras-chave: Renascimento, Maneirismo musical, Madrigal italiano, Carlo Gesualdo.

\section{The Musical Manneirism: a reflection about the proximity between Mannerism aesthetics and music}

\begin{abstract}
The Mannerism is the aesthetic reclassification of the artistic production of the final decades of the sixteenth century. When the european society underwent profound transformations that echoed in artistic language. In the musical repertoire of the period we find a select group of madrigalists whose works are close to the characteristics of Mannerism. This approach offers relevant tools to deepen their understanding. This paper reflected on the aesthetics of Mannerism and its application in the musical repertoire, reinforcing the proof of its existence and its relevance in the history of music
\end{abstract}

Keywords: Renaissance, Musical Manneirism, Italian Madrigal, Carlo Gesualdo.

\section{El Manierismo Musical: una reflexión sobre la proximidad entre la estética del manierismo y el arte musical}

\section{Resumen}

El manierismo artístico es la reclasificación estética que se hace de un segmento de obras artísticas elaboradas en las últimas décadas del siglo XVI, cuando la sociedad europea experimentó profundas transformaciones que se hicieron eco en el lenguaje artístico. En el repertorio musical de la época encontramos un grupo selecto de madrigalistas cuyas obras se acercan a las características del manierismo. Tal enfoque ofrece herramientas relevantes para profundizar su comprensión. Este artículo reflexionó sobre la estética del manierismo y su aplicación en el repertorio musical, reforzando la prueba de su existencia y su relevancia en la historia de la música.

Palabras clave: Renacimiento, Manierismo musical, Madrigal italiano, Carlo Gesualdo. 


\section{I.}

A fase final do Renascimento reservou à história da arte um período bastante peculiar. Seus artistas produziram um segmento de obras de incontestável valor artístico, cujo principal mérito é deixar seu observador em um estado misterioso que alia o prazer estético a uma sensação de desconforto. A essa expressão artística atribuiu-se o nome de Maneirismo. Seu marco inicial foi a Roma de 1520, mas seus humores e tensões se espalharam pela península italiana e encontraram como centro principal a Florença dos Medici ${ }^{1}$, não sem ter deixado traços inconfundíveis nas adjacências europeias. Sua aceitação enquanto fenômeno artístico tornou-se um dos pontos de maior dissenso entre os estudiosos e interessados em arte. Isso porque a compreensão de sua linguagem não se dá unicamente através da identificação de suas obras, exigindo um olhar cuidadoso sobre o momento artístico que a originou. A força expressiva identificada nesse momento artístico acaba tornando-se a grande protagonista dessa discussão.

Para entender o Maneirismo em seus mais amplos domínios é necessário considerar as décadas finais do século XVI como um período em que a sociedade europeia vivenciou uma de suas mais profundas mudanças estruturais ao mesmo tempo em que atingia o auge das técnicas artísticas que conhecia. Ao longo de todo o Renascimento identificamos um ininterrupto processo de estruturaçáo da linguagem. O advento da técnica a partir de conceitos mais modernos, tais como o desenvolvimento sistemático do apuro científico, propiciou a seus artistas a chance de eleger a perfeição como objetivo principal. Não por acaso a caracterização mais comum da estética do Renascimento seja a busca pela reprodução perfeita da natureza. Todo esse processo tem uma adequada tradução na corrente filosófica do Humanismo, que desenhou e conduziu o período renascentista.

No entanto, o desenlace de todo esse processo evolutivo foi uma grande crise estética a partir de meados do século XVI. Os artistas que passaram a ser identificados como do Maneirismo se distanciavam de seus pares renascentistas pois não mais objetivavam imitar a natureza, mas sim superá-la. A isso podemos denominar como a crise do século XVI, ou a crise do Renascimento.

Uma interessante reflexão nos é proposta por Arnold Hauser, em seu livro Maneirismo - a crise da renascença e o surgimento da arte moderna (1976). Logo em sua introdução, o autor traça um paralelo entre a crise do século XVI, que será ainda discutida nesse trabalho, e o seu momento atual, a segunda metade do século XX. Para ele, ambos os momentos são de colapso estético, sendo este o ponto de intersecção a partir do qual ele explicaria o renovado interesse que a estética do Maneirismo passou a exercer no século XX. Este renovado interesse também foi notado poucos anos antes no prefácio do livro O Maneirismo, de John Shearman (1967), quando o autor atesta que a volta do interesse pelas obras maneiristas seria facilmente comprovada através do exame dos preços de vendas e aquisiçóes de museus e colecionadores sobre este tema (1967, p.9).

A comparação de Hauser atinge seu ponto principal quando ele atesta ser o Impressionismo do século XX - movimento artístico revolucionário que teve em Claude Monet (1840-1926) seu principal representante - como o passo inicial a dar espaço para a redescoberta do Maneirismo. As afinidades formais do Impressionismo com o Barroco acabaram

1 Família toscana que durante o Renascimento assumiu o comando administrativo da cidade de Florença. 
por enfraquecer o que chamou de "autoridade estética do Classicismo" (HAUSER, p.15). Ou seja, na visão desse autor, existia até o início do século XX uma preponderância da estética do século XVIII, que de certa forma dificultava a aceitação do que fora feito no final do século XVI. A partir da confluência de várias estéticas mais revolucionárias, em especial o Impressionismo, permitiu-se que outras linguagens artísticas mais afastadas do que comumente se apreciava encontrassem lugar nas galerias, museus e teatros. Ressurge então, em pleno século XX, o Maneirismo artístico.

Essa reflexão nos ajuda a entender as razóes pelas quais a arte maneirista passou longo período sendo eclipsada por suas antecessoras e pelo que fora elaborado posteriormente a seu tempo, pois mesmo com a contribuição advinda da comparação efetuada por Hauser essa questão não se esgota completamente. A pergunta que ainda se coloca é: quais são os motivos que levaram as obras de arte mais antigas, como do Renascimento inicial ou mesmo do período medieval, serem mais bem aceitas e entendidas do que a produçáo do final do século XVI?

Para responder essa pergunta podemos utilizar uma vez mais os estudos de Shearman, na passagem de seu livro em que nos deparamos com a inquietante frase: "Tẫo grande é a confusão existente em nosso emprego atual do termo que uma reação perfeitamente natural dos historiadores da arte é afirmar que o Maneirismo não existe" (1967, p.13). A força maior desta afirmação escrita na década de sessenta do século passado reside na sua atualidade. Colabora com esta visão, o autor Sydney Freedberg, em seu livro Parmigiano, de 1950, dedicado ao pintor maneirista Girolamo Francesco Maria Mazzola, que ficou conhecida na história como Parmigianino (1503-1540). O autor resume logo no início do livro sua opiniáo dizendo que a grande massa de publicaçôes e conhecimentos sobre o Maneirismo consiste em generalizaçôes, algumas com acertos, mas muitas com erros inimagináveis (1950, p. 7). Ou seja, é tão complexo entender o que foi o fenômeno do Maneirismo no século XVI, que se torna mais prático desmerecer a definiçâo e encarar as obras a ele atribuída como sendo expressóes de fim de período, com todo o juízo preconceituoso e superficial que isto implica. Não se deve desconsiderar que desde a fase em que estes autores iniciaram estas pesquisas a cerca deste assunto, segunda metade do século XX, muitas outras pesquisas e entendimentos foram adquiridos. Mas as respostas alcançadas ainda não foram suficientes a ponto de permitir que o tema seja discutido sem polêmicas e negaçôes.

O próprio termo que o denomina nos leva a incorrer em uma série de questóes e armadilhas conceituais. Consta que sua origem etimológica, a palavra italiana maniera (cuja tradução para o português pode ser estilo), era muito usada durante o Renascimento com o seu sentido absoluto. Ou seja, algo poderia ter ou não estilo. O que o torna emblemático nesta investigação é o fato deste atributo ser visto como algo elevado ou depreciativo, dependendo da visão de quem o utiliza.

Temos como exemplo desta complicação conceitual a carta escrita pelo pintor italiano Rafael Sanzio (1483-1520) e Baldassare Castiglione (1478-1529) em 1519 para o papa Leão X a respeito da arquitetura de Roma (HARRAN, 1969, p. 524). No documento, os remetentes reclamam serem os edifícios romanos "privados de toda graça e sem nenhum estilo". A leitura da frase no idioma original escrito por eles: Privi di ogni gratia, senza maniera alcuna, nos ajuda a compreender o valor que dispensavam ao atributo do estilo. Alguns anos depois, Giorgio Vasari (1511-1574) o renomado artista e intelectual florentino, corrobora esta visão positiva do termo ao inclui-lo como uma das cinco qualidades que, "por serem mais altamente desenvolvidas na arte do século XVI do que na do século XV, conferiam superioridade ao seu período" (SHEARMAN, 1978, p.20). 
No entanto, quase concomitantemente encontramos documentos atribuindo a existência de maniera algo deletério à expressão artística. Por exemplo o escritor veneziano Lodovico Dolce (1508-1568) que denunciava a tendência, segundo ele, deplorável da redução da criação artística a um estereótipo à maniera (TERPENING, 1997). O próprio Vasari que por vezes atribuiu ao que ele chamava de excesso de estilo, uma abstração perigosa à expressão artística.

Não há dúvidas de que termos utilizados com o sentido oposto são comuns, tanto no campo literário e acadêmico como no senso comum. Especialmente quando se infere a abrangência de seu uso, como no exemplo de Vasari que demonstra atribuir ao estilo algo valoroso, mas passa a depreciá-lo quando o identifica em exagero. Porém, no caso do Maneirismo, a complexidade em seu entendimento é tamanha que até mesmo esta dualidade conceitual concorreu para torná-lo ainda mais misterioso.

Se a própria terminologia nos rende uma séria de questôes, sua caracterização torna-se um assunto ainda mais complexo. O parâmetro que se estabelece sobre a caracterização do Maneirismo é que esta estética adveio não de uma ruptura, mas sim da descaracterização do que a precedeu. Isso nos indica que a estética nasceu a partir da sofisticação da linguagem artística já efetiva na época, sem que a mesma tenha sido reinventada. O resultado prático é a presença, desde os primeiros estágios, de um elevado grau de virtuosismo, sendo a grande diferença o uso que se fez dele. Uma forma direta de se demonstrar essa diferença é compararmos duas obras representativas, uma do Renascimento e outra do Maneirismo.

Um dos auges da escultura renascentista é o David de Michelangelo (1475-1564). Escultura produzida pelo artista entre os anos de 1501 e 1504, que retrata o herói bíblico Davi com tamanha precisão e perfeição que até hoje surpreende quem se vê diante da estátua de mármore. Destaca-se que Michelangelo ainda estava em sua fase renascentista, pois o próprio também se tornaria um ícone do Maneirismo em obras tardias. O que chama atenção nesta escultura é a reprodução perfeita do corpo humano, com detalhes preciosamente esculpidos sempre balizados pelo equilíbrio e simetria dos traços.

Figura 1 - Michelangelo Buonarotti, David (1501-1504), Galleria dell'Accademia (Florença)

Fonte: Wikipedia ${ }^{2}$

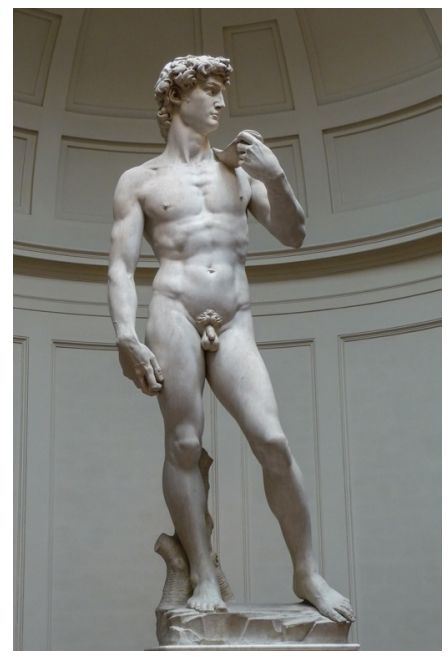

2 Disponível em $<$ https://pt.wikipedia.org/wiki/David_(Michelangelo)\#/media/Ficheiro:'David'_by_ Michelangelo_JBU0001.JPG >. 
A poucos metros da Galleria dell'Accademia, onde se encontra o original de Michelangelo, temos na Loggia dela Lanzi, em Florença, a escultura O Rapto da Sabina, de Giambologna (1529-1608). Essa escultura terminada em 1583, que retrata uma lenda romana, apresenta a mesma virtuosidade técnica e a perfeição encontrada na obra de Michelangelo. Porém, pela forma como foi elaborada, sua dramaticidade acaba apresentando uma realidade deturbada, descontruída.

Figura 2 - Giambologna (Jean Boulogne), O Rapto das Sabinas (1574-1583), Loggia dei Lanzi, (Florença)

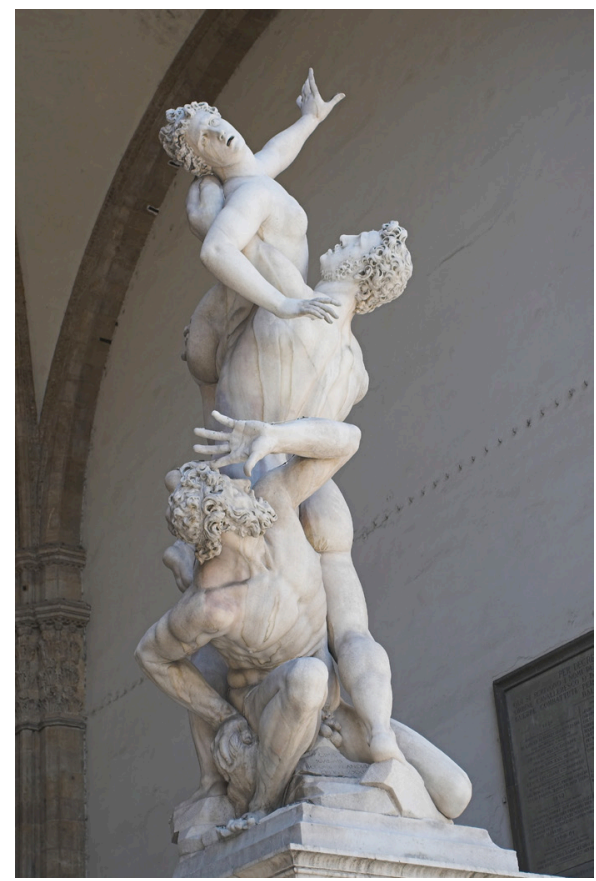

Fonte: Wikimedia Commons ${ }^{3}$

$\mathrm{Na}$ comparação entre as duas obras temos uma demonstração in loco de como se deu o processo de desconstrução que representa o Maneirismo. As semelhanças técnicas na elaboração das duas esculturas são inequívocas, mas Giambologna opta por abandonar o ideal simétrico e equilibrado utilizado por Michelangelo em seu Davi, utilizando recursos que vão totalmente de encontro a isso. Tais como: a figura serpenteada; a retratação do corpo humano com tensôes musculares; o eixo central da obra retorcido; entre outros. Esses elementos resultam em uma ação muito mais dramática e tensa do que a figura retratada por Michelangelo e a responsável pela sensação de "desconforto" que fora citado no início desse texto. Com esses efeitos, temos a caracterização da estética do Maneirismo.

Pode-se considerar normal que após um período regido pela clareza e equilíbrio das linhas - um período clássico - como foi o Renascimento, o ideal artístico caminhe para uma fase em que estas características sejam negadas. Mas o que se observa no Maneirismo vai além dessa resposta natural do processo. Essa estética nos apresenta, talvez pela primeira vez de forma relevante, a arte pela arte, sem a pretensão de fazer dela uma representação de

3 Disponível em <https://upload.wikimedia.org/wikipedia/commons/f/fd/Giambologna_sabine.jpg>. 
outra coisa. Em outras palavras, o artista maneirista não esperava com sua obra retratar algo natural, nem mesmo cumprir nenhuma função objetiva, mas sim preencher a realidade com algo não realista. Hauser já havia demonstrado em sua pesquisa que os artistas maneiristas eram inspirados menos pela natureza do que pelas próprias obras de arte. Estavam menos sob a influência dos fenômenos naturais do que pelas criaçôes artísticas (1976, p.33). Este distanciamento da arte objetiva, da arte útil, torna o Maneirismo como um fenômeno único, e nos demonstra através deste seu antinaturalíssimo a complexidade que o envolve.

Toda essa descrição do que consiste a estética do Maneirismo passa a fazer mais sentido quando é inclusa em um momento bastante peculiar da história social da Europa, o século XVI. Momento em que a sociedade viveu uma profunda transição, desvencilhando-se das estruturas feudais do longo período medieval para uma estrutura social mais moderna. Não sendo surpresa que uma série de abalos comportamentais e confusôes ideológicas se fizeram presentes em não raros momentos nesse processo.

O principal de todos esses abalos diz respeito à questão religiosa. Temos na Reforma Protestante, iniciada por Martinho Lutero (1483-1546) em 1517, e na sua consequente Contra Reforma, empreendida pela Igreja Católica, como o auge destas crises. Certamente elas nos evidenciam alteraçóes no modo de se pensar o ser humano que não se limitam à experiência religiosa, mas sim ao próprio papel do homem no mundo moderno. A influência que esse processo exerceu na linguagem artística foi determinante para o advento do Maneirismo.

Uma explicação artística para se entender a origem da crise do Renascimento está em sua ligação com o mundo da Antiguidade Clássica - Greco/Romano. Os artistas e pensadores do período tinham como modelo a ideia de equilíbrio e perfeição que lhes foi legado pela tradição clássica. Todo o arcabouço arquitetônico, poético e filosófico das reminiscências clássicas, mais do que inspirar, operavam como alicerces à estética renascentista. No entanto, o ideal de mundo que se tentava restaurar a partir do século XIV começou a náo mais se sustentar na medida em que a sociedade europeia crescia e se alterava, causando a crise existencial que se instaurou na fase final do período.

De fato, o mundo antigo apresentava uma série de características que se tornariam simplistas frente ao mundo pós-medieval. Basta nos concentrarmos na própria questão da fé para identificarmos essa incoerência. Enquanto a sociedade clássica acreditava em conceitos razoavelmente simples e diretos quanto à morte e o que ocorreria depois, o mundo pós medieval, que havia passado por mais de mil anos de experiência católica e todos os dogmas e complexidades que viriam a partir disso, tornara-se muito mais complexo e cheio de dúvidas existenciais. Logo, o encaixe entre estas visões de mundo estava fadado ao insucesso, e foi na expressão artística que esta crise melhor se expressou. Conforme cita o autor Mario H. Gonzales em seu artigo Arnold Hauser e a Literatura Espanhola (2010), o Maneirismo acabou ao mesmo tempo com os universos criados pela Antiguidade, pela Idade Média e pela Renascença (2010, p.126).

Sua abrangência se deu em praticamente todas as áreas artísticas, com maior ênfase nas artes visuais. Isso não quer dizer que a importância nas demais expressões tenha sido menor, basta a constatação de que a literatura maneirista pode ser medida pelos seus dois principais nomes, William Shakespeare (1564-1616) e Miguel de Cervantes (1547-1616) (HOCKE, 2005, p. 147), para termos uma dimensão de sua importância. Mas é na música que encontramos o caso mais complicado desse assunto, pois as dúvidas e desacordos que ainda persistem nesta discussão são mais sólidos que os avanços alcançados nas últimas décadas de pesquisa. 
A música difere das demais expressões artísticas por seu caráter efêmero e abstrato. Mesmo com a utilização do texto em suas composiçôes, como no caso da música vocal, seu intuito artístico poucas vezes caminha em prol da objetividade narrativa ou descritiva. Pode-se dizer que a linguagem musical busca levar seu ouvinte mais a sentir algo do que a entender o mesmo, o que a torna significativamente subjetiva.

Há, ainda, outro fator relevante para que se explique a dificuldade extra que a arte musical tem em se encaixar na estética do Maneirismo. Conforme já dito neste estudo, a ligação do Renascimento com o que se conhece da cultura da antiguidade é direta. E justamente nessa ligação que se alicerçou os principais pilares do entendimento da estética maneirista, pois sendo o Maneirismo a representação artística da crise deste conceito clássico dentro do século XVI, a comparação entre as estéticas torna-se um mapa para seu entendimento. Uma escultura renascentista tem na similaridade que apresenta com uma escultura romana sua característica mais forte, enquanto uma escultura maneirista tem justamente na incoerência estética com o mesmo exemplo romano a sua também principal característica. $\mathrm{Na}$ comparaçáo entre os dois períodos é que reside o entendimento principal.

Inexiste na linguagem musical exemplos ou conhecimentos sólidos sobre a prática musical da Antiguidade. Sólidos, a ponto de nos permitir utilizá-lo como parâmetro de comparação nesse assunto. Isso faz com que a compreensão da música do Maneirismo fique prejudicada frente a todas as outras expressóes artísticas. Porém, como convém a um tema táo complexo e ainda inicial como é a música do Maneirismo, outros elementos surgem na discussão para nos impulsionar a continuar o debate e avançar nessa pesquisa.

Uma das mais importantes pesquisadoras do Maneirismo que assumiu, mediante uma incansável investigação cientifica, o repertório de determinados compositores do final do século XVI como sendo sim representantes desta estética artística, chama-se Maria Rika Maniates. Em seu livro Mannerism in Italian Music \& Culture, 1530-1630, de 1979, levanta uma constatação que contribui nessa discussão. Segundo ela, dadas as alteraçóes na elaboração musical do período final do Renascimento, em especial a força expressiva atingida pelo enlace entre música e texto (princípio básico para se entender os madrigalistas tardios), a música sai do chamado quadrivium científico - aritmética, geometria, astronomia e a própria música - onde se estabeleceu desde a antiguidade clássica, para passar a integrar o trivium - lógica, retórica e gramática (MANIATES, 1979, p. 115). A importância dessa constatação da autora está no fato de conseguir incluir a arte musical naquele mesmo parâmetro que acabou tornando-se um dos poucos consensos no entendimento do Maneirismo - a comparação com a estética da Antiguidade. Portanto, aceitando-se essa conclusão de Maniates é possível também comprovar que a música do final do Renascimento passou a ter uma reclassificação estética.

Por fim, é necessário registrar que mesmo que todas as informaçóes levantadas nesta introdução sejam desconsideradas, ainda existirá de fato um repertório musical elaborado nas últimas décadas do século XVI que se diferencia de tudo que fora composto antes e do que veio depois. Este repertório, cujos principais representantes são os chamados madrigalistas tardios, apresenta características musicais e expressivas de tal forma revolucionárias que configuram um capítulo à parte na história da música.

É justamente por não se encaixarem de forma efetiva na estética de seu próprio período, o Renascimento, e tampouco apresentarem ligaçóes coerentes com a música do Barroco, que estas obras acabaram ficando à margem dos principais estudos e tiveram sua apreciação prejudicada por muito tempo. Compositores como Cipriano da Rore (15151565), Luzzasco Luzzaschi (1545-1607), Lucca Marenzio (1553-1599) e Carlo Gesualdo 
(1566-1613), elaboraram um tipo de escrita musical que permitiu a eles se distanciarem da estética do Renascimento ao mesmo tempo em que caminhavam em uma direção diferente da que chegaria à música barroca. A tentativa de enquadrar a obra destes madrigalistas dentro da estética do Renascimento exige um sem número de concessóes que acabam por desqualificar a própria obra, sendo mais comum a não inclusão em grupo estético nenhum, tratando cada obra como um fenômeno individual.

A partir da experiência pessoal desse pesquisador com o repertório em questão, especialmente os madrigais escritos pelo compositor Carlo Gesualdo, comprovou-se na prática que quando são incluídos no contexto do Maneirismo, com todas as suas peculiaridades e, por vezes, excentricidades, o benefício do diálogo com um universo artístico maior é decisivo na compreensão mais ampla e efetiva da linguagem. Isso porque uma linguagem artística táo sofisticada como o Maneirismo, com total influência das demais expressóes, não permite sua efetiva compreensão quando está isolada de um contexto mais amplo.

Portanto, partindo dos conhecimentos já existentes em relação ao tema, este artigo tem por propósito elencar e refletir sobre as principais características da música do Maneirismo. Serão considerados aspectos técnicos como a questão harmônica e a escrita poética, além de se identificar e discutir exemplos que nos revele na prática em que consiste a música do Maneirismo. Não consta, no entanto, o objetivo de elucidar completamente a linguagem, e por impossível que é, não se objetiva esgotá-lo completamente. O que está contido na sequência desta introdução é a interligação dos conhecimentos técnicos que já existem com exemplos relevantes do repertório, ampliando a discussão e abrindo espaço para outros trabalhos. Tendo em vista a frase de Shearman, já citada, dizendo que diante da confusão sobre o tema o caminho mais fácil é negar a existência da estética do Maneirismo, este artigo propóe assumir sua existência e avançar um pouco mais em seu entendimento.

\section{A Música do Maneirismo}

A caracterização da música do Maneirismo nos impóe alguns conhecimentos prévios, sem os quais esse objetivo se torna mais difícil. O principal deles é entender o que foi e até onde chegou a música do Renascimento. Tratando-se de uma linguagem musical não advinda de uma ruptura, mas sim de uma descaracterização dos propósitos vigentes em prol de um novo objetivo artístico, a música do Maneirismo é em grande parte revelada pelos conhecimentos que temos do que a precedeu.

Se analisarmos a história da música do ocidente através de uma linha evolutiva, identificaremos como seus dois polos principais os sistemas de composiçáo modal e tonal. Não se exclui nessa compreensão todos os demais sistemas que foram utilizados pelos principais compositores, especialmente a partir do século XX, por mera simplificação, mas por ser através dos citados que podemos organizar de forma mais coerente o caminho que a escrita percorreu. A partir desta linha evolutiva, podemos tirar algumas reflexóes.

A elaboração musical identificada durante todo o período Medieval nos apresenta um incontestável predomínio da escrita sacra católica. Esse repertório pode ser descrito basicamente como monódico e modal (canto gregoriano), e se impôs como hegemônico até meados do século XIII. Ressalva-se que a caracterização da música medieval como essencialmente monódica não desconsidera a existência de outras práticas também importantes, especialmente nas expressóes seculares do período. Mas para o que se objetiva nessa comparação, a monodia gregoriana é a mais relevante. 
Seguindo na análise histórica, temos o sistema tonal assumindo a preponderância que antes era modal e mantendo sua importância até os dias atuais. No entanto, seu estabelecimento efetivo se deu apenas em meados do período Barroco, assim mesmo com uma série de condicionantes impostos pelo uso ainda constante da afinação desigual e outros elementos inerentes àquele período. Ou seja, tendo o sistema modal entrando em declínio no fim da Idade Média e seu sucessor, o tonal, estabelecendo-se totalmente apenas no Barroco avançado, encontramos durante o Renascimento um período de transição. A música do Renascimento faz parte de uma grande mudança estrutural entre os sistemas de composição, o que nos permite considerá-la como uma linguagem experimental.

Dentro dessa transição encontramos de forma clara o ponto de partida: a escrita monódica e modal bem exemplificada pelo canto gregoriano; e também podemos caracterizar com propriedade seu ponto de chegada: a melodia acompanhada do Barroco. Já os caminhos utilizados pela escrita nessa fase transitória são menos claros.

A principal caracterização que perpassa todo o período renascentista na música é a polifonia vocal italiana. Essa escrita advinda da uniáo entre a técnica polifônica trazida pelos compositores franco-flamengos e a tradição melódica dos compositores da própria península italiana foi a responsável por encaminhar todo o desenvolvimento da música ao longo do período (xxx). É através desse repertório polifônico que conseguimos analisar com mais propriedade o processo de exploração das novas resultantes harmônicas conquistadas pela prática da musica ficta (utilizaçáo de notas náo pertencentes a escala escolhida) e de outros novos procedimentos que permitiram seu desenvolvimento.

Porém, quando se analisa de forma mais ampla o repertório relevante do Renascimento é possível identificar que em sua fase final esse experimentalismo assumiu maior protagonismo. Evidencia-se que os compositores dessa última fase estavam mais ocupados em promover efeitos sonoros inusitados sem um propósito evolutivo, sendo o experimento pelo experimento. Ou ainda, o evento sonoro experimental caiu no gosto dos compositores e ouvintes do período.

Nesse ponto da reflexão identificamos uma coerência entre a definição do Maneirismo enquanto expressão artística - a arte pela arte - com a explicação que se dá para o repertório tardio da música do Renascimento, especialmente na escrita do madrigal italiano. O que chama a atenção nesse encontro de definições é que foram alcançadas através de tentativas em se entender o que ocorreu esteticamente naquele momento, e ambas as explicaçóes se mostram como as únicas capazes de nos apontar um entendimento coerente sobre as décadas finais do século XVI. Ou seja, a crise estética identificada nas demais artes que exigiu sua reclassificação estética, também é percebida na escrita musical através do experimentalismo puro, quando o efeito sonoro cada vez mais abrupto e descolado de qualquer intenção harmônica se torna relevantemente presente. Eis que nos encontramos diante da Música do Maneirismo.

\section{O repertório}

$\mathbf{E}_{\mathrm{m}}$ se tratando de uma estética tecnicamente sofisticada e extremamente personificada nos artistas que a compóem, a música do Maneirismo se revela mais nos pormenores de cada compositor do que na alusão geral de sua escrita. Tamanha é a importância individual de cada um, que náo seria demais nos referirmos a Maneirismos -no plural - ou ainda, um Maneirismo para cada músico. Soma-se a isso a enorme complexidade, já eviden- 
ciada nesse texto, em se entender um repertório musical forjado a partir do virtuosismo da escrita polifônica renascentista, com objetivos artísticos distintos. Uma linguagem baseada nos efeitos sonoros como principal elemento retórico.

Depreende-se que o caminho mais seguro a ser escolhido para a sequência dessa investigação seja nos concentrarmos em exemplos de compositores maneiristas e suas respectivas obras. Iniciaremos essa etapa da pesquisa com Cipriano da Rore (1516-1565), compositor italiano que iniciou em sua obra muitas inovaçōes da escrita madrigalesca e pode ser considerado como o primeiro representante relevante da música do Maneirismo. Rore torna-se um compositor importante não só pela beleza e requinte de sua obra, mas pelas inovaçóes que implementou justamente no momento de maior experimentalismo no século XVI. Não foi por acaso que Alfred Einstein, em seu extenso trabalho sobre o madrigal italiano, afirmou não haver uma só alteração na escrita do madrigal italiano tardio que não tenha sido antecipada por Rore (EINSTEIN, 1971). Sua escrita se aprofundou de tal forma que passou a distinguir-se do madrigal "clássico" que prevalecera até a parte inicial daquele século (xxx). Rore se insere na transiçẫo entre estas duas fases, e sua grande contribuição foi ter indicado o caminho que viria a ser seguido pelos demais maneiristas.

Podemos medir a importância de sua obra através das citações e opiniōes de autores especializados no assunto. Suzan McClary, em seu livro Modal Subjectiveis (2004), dedica um capítulo à escrita de Rore, e chega a comparar sua importância dentro do Renascimento ao que foi Beethoven para o Classicismo (McCLARY, 2004, p. 101). A própria autora Maria Rika Maniates, em seu importante compêndio sobre a música do Maneirismo, destaca Rore como sendo o primeiro compositor a incorporar em seu estilo a força de sua própria inspiração pessoal (MANIATES, 1979, p. 297), constatação que dentro do universo do Maneirismo assume importância sem igual.

Muitas são as inovaçôes que se atribui a Rore. Talvez a mais difundida seja a alteração do padrão de escrita do madrigal italiano de quatro para cinco vozes ( $\mathrm{xxx}$ ). Mas foi em seu experimentalismo harmônico, que seu viés maneirista mais se pronunciou e sua obra passou a influenciar e contribuir no desenvolvimento dessa estética. Foram em seus madrigais que se identificou os primeiros traços de uma escrita harmonicamente ousada no século XVI. Evidentemente, uma constatação genérica como esta não pode ser feita a partir de números e nem considerada literalmente, uma vez que facilmente se identificaria obras anteriores a Rore cuja escrita musical se encaixa nesta descrição. Mas ao considerarmos sua importância dentro da história da música, podemos atribuir a Rore o título de precursor da escrita tardia.

Um exemplo representativo desta questão encontra-se no madrigal Calami sonum ferentes, que Rore publicou pela primeira vez em $1555 \mathrm{em}$ um livro organizado pelo compositor Orlando di Lassus intitulado Il primo libro dove si contengono Madrigali. Conforme nos indica Einstein, Lassus pode ter tido contato com esta obra a partir de seu encontro com Rore nos anos de 1554 e 1555 em Ferrara, e consciente de sua linguagem revolucionária, tratou de inclui-la em sua antologia (EINSTEIN, 1971, p. 414).

Não são necessários mais do que os primeiros compassos do madrigal escrito para vozes masculinas para percebermos se tratar de uma linguagem harmônica inovadora e ousada. A escala utilizada pelo compositor é quase didaticamente apresentada em seu estágio cromático, o que enfraquece e até mesmo inviabiliza qualquer sensação de repouso. $\mathrm{O}$ que mais chama a atenção e coloca este madrigal em uma posição de destaque no período é a utilização dessa escrita cromática em uma obra com predominância imitativa, e não homofônica. Por terem se desenvolvido principalmente a partir da prática da musica ficta, as alteraçóes cromáticas, até então, estavam mais associadas à escrita acordal, ou vertical. 
Soma-se a isto o fato de a escrita imitativa predominante até a fase central do período ter uma grande preocupação com o equilíbrio e a simetria das linhas, o que colaborava para manter as alteraçóes melódicas em um nível comedido.

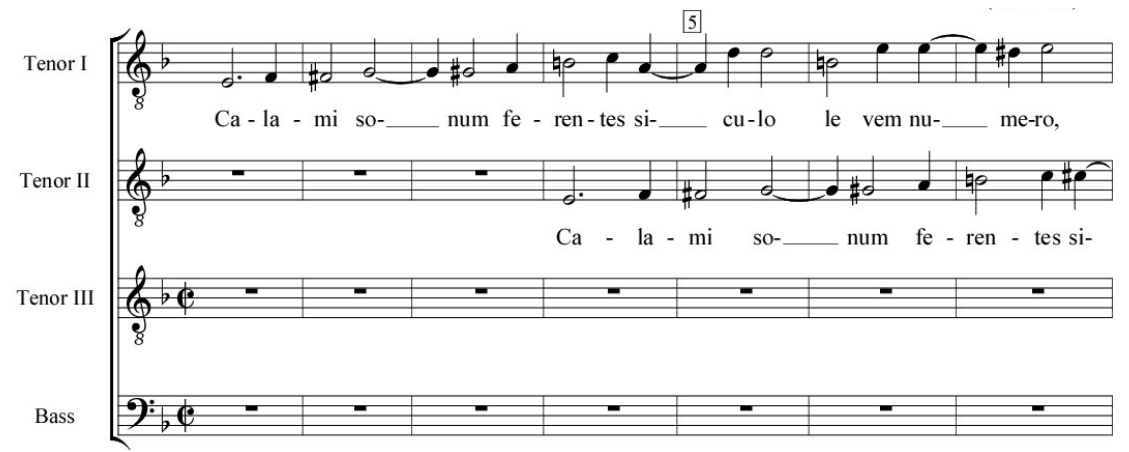

Figura 3 - Calami sonum ferentes - c. 1 - 7

Apesar de ser sua escrita cromática o que mais chamou a atenção dos estudiosos da música até hoje, sua maior contribuição para a escrita da música do Maneirismo reside no tratamento que dispensou ao texto poético. Rore inaugura uma nova forma de relacionar a música e o texto, quando a representação do sentido estrito de cada termo passa a ser substituída pela intenção em se representar o ambiente, ou o humor de cada passagem textual.

O que aqui se coloca como a forma antiga de se retratar o sentido dos termos na música fora aperfeiçoada poucos anos antes, com as composiçóes de uma geração importante de madrigalistas tais como Adrian Willaert (1490-1562) e Giosefo Zarlino (1517-1590). Nas obras desses madrigalistas a grande inovação era a indicação exata de onde cada sílaba do texto deveria ser cantada na frase musical, o que indica a preocupação que eles dispensavam à prosódia musical $(\mathrm{xxx})$. Na escrita elaborada por Rore percebemos um aprofundamento considerável nessa preocupaçáo, quando o compositor passa a retratar musicalmente o sentimento contido dentro da narraçáo. Mais uma vez nos deparamos com uma situação que vai ao encontro da caracterização do Maneirismo artístico, o uso da mesma ferramenta utilizada pelos renascentistas, mas com abrangência maior.

Um exemplo representativo temos em $\mathrm{O}$ sonno, um dos madrigais mais conhecidos de Rore.

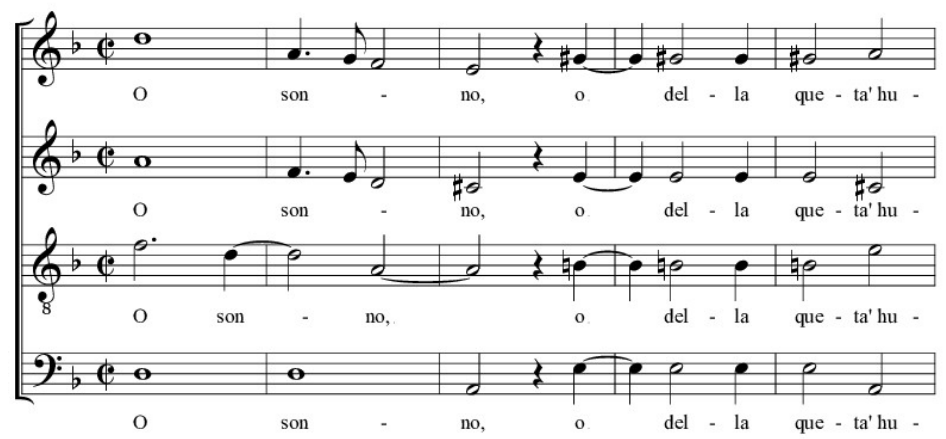

Figura 4: Madrigal O sonno - c. 1 - 5 
A música proposta por ele para o soneto de autoria de Giovani della Casa (15131556), realiza um tal enlace entre as imagens poéticas e a escrita sonora, que levou Alfred Einstein a referir-se a ela como "uma grandiosa declamação, não governada pela rima, mas sim pelo sentido" (1971, p. 417, tradução nossa). O uso de um ritmo harmônico lento e poucos, mas precisos, movimentos melódicos descendentes nos três primeiros compassos produzem sonoramente uma imagem que remete ao ato de dormir, evocado na primeira frase do texto. A inovação de Rore é descrever uma imagem abstrata, dissociada, na origem, do som. Ou seja, o compositor não retrata uma simples imagem sonora, como se fazia antes, mas todo um ambiente sonoro.

É a partir deste domínio de capturar e reproduzir na música a essência do texto, que foi construído todo esse repertório do final do século XVI. Está nessa sutil e sofisticada manipulação das resultantes harmônicas em prol de um efeito retórico que coadune música e texto, a melhor tradução da música do Maneirismo. Pois, abrem-se assim condiçóes para a elaboração musical subjetiva, em que o sentido psicológico de cada intenção poética é retratado musicalmente com todas as ferramentas musicais disponíveis aos compositores daquele momento.

Outra característica inerente ao Maneirismo como um todo e que não passa despercebido pela sua vertente musical diz respeito ao alto nível intelectual de seus autores e que transborda em suas respectivas obras. Um exemplo revelador sobre isso é o ciclo de madrigais escritos por Orlando di Lassus intitulado de Prophetiae Sybilarum.

Temos nesses 12 motetos seculares, como os designou Maniates (1979: p. 310), um considerável monumento à música do Maneirismo. Até mesmo a data exata de sua composição está até hoje cercada de mistérios e detalhes desconhecidos que fariam a diferença caso fossem desvendados, pois a primeira edição deu-se apenas em 1600, alguns anos após a morte do compositor. A dúvida principal é se Lassus os escreveu antes de conhecer a peça, a pouco retratada nesse texto, de Cipriano da Rore Calami sonum ferentes. A discussão que fora muito bem encaminhada por Lowinsky em seu livro sobre a escrita do século XVI, se detém em qual dos compositores exerceu influência sobre o outro, determinando, portanto, quem teria a primazia da escrita cromática avançada do Maneirismo. A opinião de Lowinsky, que é acompanhada por esse pesquisador, é que mesmo não havendo comprovaçóes documentais para tal afirmação ele acredita ter sido o ciclo escrito por Lassus após conhecer o madrigal de Rore, uma vez que o compositor seria muito jovem para ter escrito antes (LOWINSKY, 1962, p. 89). O autor defende essa opinião a partir da observação do desenvolvimento da escrita de Orlando de Lassus.

Nessas 12 peças mais seu prólogo, Lassus surpreende até pela escolha destes textos e todo o arcabouço filosófico que traz à tona. $\mathrm{O}$ mais relevante para uma pesquisa sobre o Maneirismo é constatar que o compositor se interessou por um texto que consegue se situar com propriedade exatamente entre a Antiguidade Clássica e o Cristianismo, justamente o recorte temporal que também se relaciona com a estética maneirista e a crise do Séc. XVI. As Sibilas são doze profetizas da mitologia Greco-Romana que se notabilizaram por fazerem previsões sobre o nascimento, paixão e morte de Cristo. $\mathrm{O}$ fascínio que passaram a exercer sobre o cristianismo foi tanto que podemos medi-lo pela quantidade de representaçóes que existem delas nos templos cristãos. Certamente, a mais notável foi sua inclusão por Rafael Sanzio (1483-1520) nos afrescos da Capela Sistina (MANN, 2004, p. 86). Sendo uma lenda da Antiguidade fazendo referências, e de certa forma respaldando, o que seria o centro da doutrina cristã - Jesus Cristo - essas personagens trazem em si uma conexão muito cara para o Maneirismo e toda a sua complexidade filosófica. 
A elaboração musical proposta por Lassus para essa lenda, somada a todas as implicaçóes trazidas pela escolha desse tema, nos apresenta o auge da Musica Reservata e consequentemente uma representação fiel da música do Maneirismo.

Figura 5 - Carmina Cromático - Prólogo do ciclo Prophetiae Sibyllarum
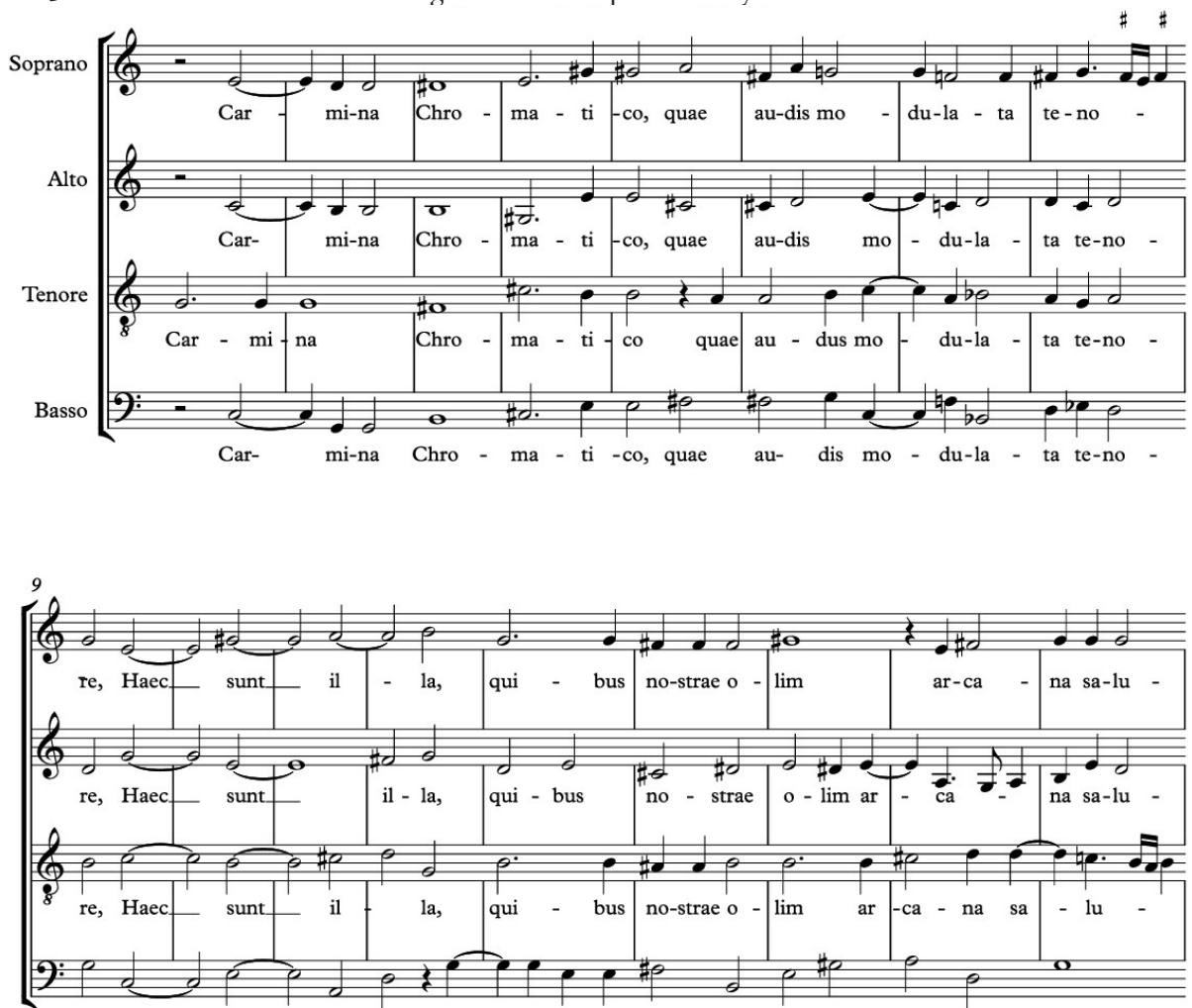

re, Haec_ sunt_ il - la, qui - bus no-strae o - lim ar - ca - na sa - lu -

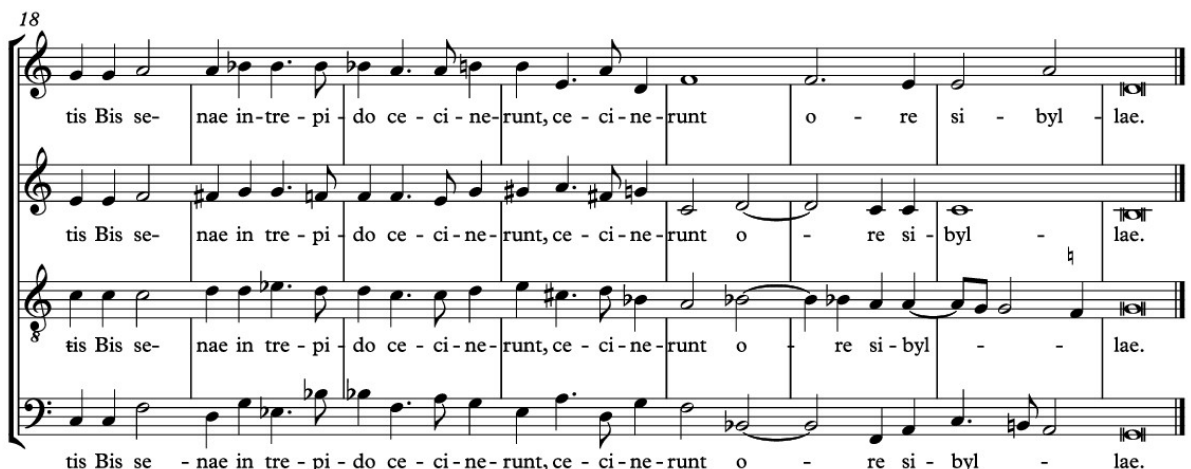

Fonte - Elaborado pelo autor

Bastam apenas os 25 compassos (das edições modernas, visto que na época não se utilizavam barras de compassos) do prólogo desse ciclo, com o sugestivo título de Carmina 
chromatico ( Canções cromáticas), para identificarmos o quão inovador foi a escrita dessa obra. Em seus nove primeiros compassos temos os doze semitons da escala didaticamente utilizados. O centro harmônico da obra é a escala mixolidia em G, a qual o compositor afirma e reafirma em trechos estratégicos da obra, tais como o final da primeira frase (c. 9) e o final definitivo no compasso 25. Porém, constrói resultantes triádicas ao longo das frases que apontam para vários outros caminhos, confundindo o entendimento geral da escrita. Conforme anotou Howard Brown em seu livro Music in the Renaissance na parte em que trata do final desse período, quando se encerra o prólogo o ouvinte já está totalmente perdido em sua orientação tonal (1976, p. 304). Esse pesquisador, amplia essa citação para: ...totalmente perdido em sua orientação tonal e modal.

O que torna esse ciclo ainda mais interessante e revelador para a estética do Maneirismo é que Lassus mantém o "jogo" proposto em seu prólogo, e nas doze peças seguintes, cada uma dedicada a uma Sibila e sua profecia, reforça a escrita cromática, solidamente alicerçada em movimentos harmônicos bruscos e inesperados. A leitura musical que o compositor nos propóe dessas profecias e suas misteriosas autoras configura-se em uma representação exata do quão sofisticado e complexo se tornou o discurso musical do Maneirismo. Mas Rore e Lassus acabam se colocando como compositores do que poderíamos considerar o Maneirismo inicial. O primeiro por uma questão cronológica, situa-se no início do movimento estético, e principalmente por ter sido o precursor de elementos importantes da escrita aqui considerada maneirista. Lassus, por outro lado, estabelece-se como um maneirista inicial, pois sua obra de tão extensa e ampla acaba apresentando muitas características, algumas muito próximas do Maneirismo, como a aqui levantada, e outras mais afastadas. Entre os anos de 1580 e 1600 encontramos o que é considerado o Maneirismo maduro, ou o estabelecimento efetivo da estética no campo musical. Nesse período, temos na escrita musical o desenvolvimento do que fora encontrado na escrita de Lassus e, especialmente, nas inovaçóes de Rore. Há dois elementos, muito significativos para essa fase, que nos dão uma dimensão do que estava ocorrendo.

O primeiro elemento é o fato de o repertório equilibrar - termo controverso para o assunto em questão - o estilo inovador e dramático que caracteriza a música do Maneirismo, ao mesmo tempo em conservava traços da elegância e do equilíbrio da escrita polifônico do alto Renascimento, muito bem representado pelo estilo veneziano (MANIATES, 1979, p. 332). Percebe-se com interesse que o estabelecimento desse equilíbrio entre a sobriedade polifônica, herança do Renascimento, com a audaciosa escrita tardia do Maneirismo aconteceu especialmente na fase já estabelecida dos compositores maneiristas. O que comprova o amadurecimento da estética musical.

O segundo elemento é a identificação do que ficou conhecido como "música visual" - conceito estabelecido pela autora Maria Rika Maniates e aceito pela maior parte dos demais estudiosos dedicados a esse assunto. Esse conceito diz respeito ao aprofundamento da prática observada em Rore de estabelecer uma tal conexão entre a música e o texto que extrapolasse a simples imitação da palavra. Para tanto, caminhou-se em direção à captura do espírito da narração poética e a tentativa de retratá-la no ambiente musical proposto da forma mais realista possível. Estando o ambiente Maneirista cada vez mais aprofundado e eclético, percebe-se cada vez mais o uso de procedimentos musicais cujo intuito era visual, transferindo para a partitura parte da intenção do texto. Seria como se o compositor maneirista se transforma-se em um artista visual e desenha-se em sua música parte do sentimento que gostaria de transformar em som. Mais uma vez nos deparamos com as definiçóes gerais da estética dentro do universo musical - a arte pela arte. 
O compositor que representa com sua obra a fase mais madura e estabelecida do Maneirismo na música é Luca Marenzio (1553-1599). Sua relação com os poetas de seu tempo nos dão uma dimensão da importância que o compositor dedicava à palavra, ao termo poético. Um exemplo elucidativo era sua relação com a obra do poeta Giovanni Battista Guarini (1538-1612) e a utilização revolucionária que fez de seu poema Tirsi Morir Volea (xxx). Outra obra que muito contribui para esse entendimento é seu madrigal Scaldava il sol, escrito sobre um poema de Luigi Alambani (1495-1556). O texto, também conhecido como Favola di Narciso, traz um sem número de imagens associadas à narração poética que foram muito bem capturadas e descritas pela música proposta por Marenzio. Especialmente o ambiente quente e letárgico que refere ao momento do sol mais quente, ou o meio dia.

Figura 6: Scaldava Il Sol - c. 1-5

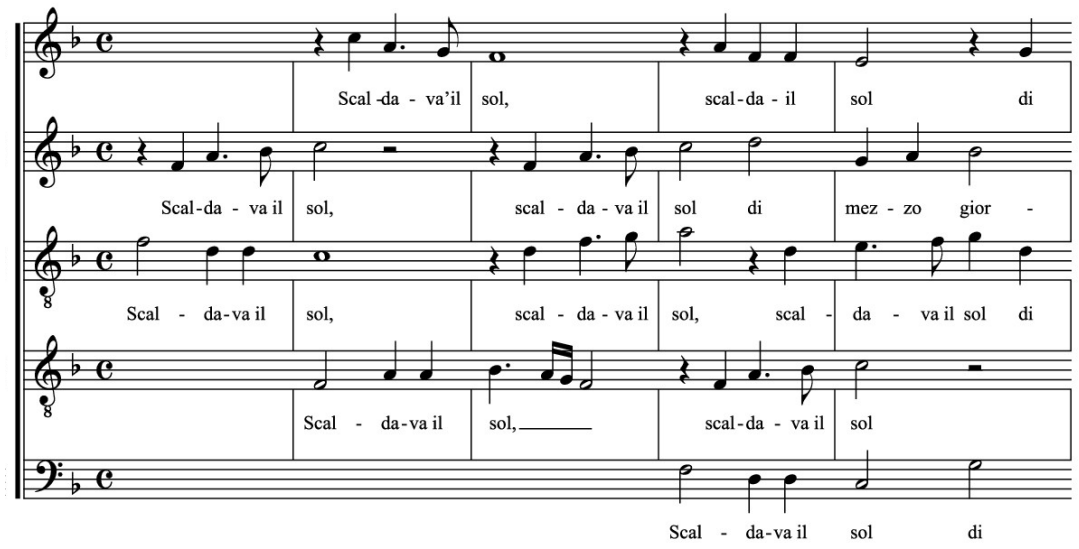

Fonte - Elaborado pelo autor

A frase textual que abre o madrigal Scaldava il Sol, que em uma tradução livre poderia ser "O Sol esquentava”, nos remete a mais de um ambiente. Por subjetiva que é a indicação, poderíamos pensar em um momento de calor em que predomine tanto a alegria e a excitação, como um ambiente tórrido e de desesperança. Mas Marenzio se ocupa em resolver essa questão abstrata elaborando uma passagem musical que direciona nossa sensação para o que ele, certamente, gostaria que sentíssemos. O ponto de imitação desses compassos é preciso, mas vagaroso. Sua sustentação se dá por tríades bem sustentadas e com um ritmo harmônico também lento. A união entre essa figura imitativa e o contexto harmônico produz uma sensação de ilusão, como se ao ouvir esses compassos fossemos arremetidos para uma paisagem desértica e estivéssemos sendo acometidos por uma alucinação. À parte ao individualismo de cada um que escute a abertura dessa obra, podemos descrever a frase inicial do compositor como produzindo um sentimento de letargia, sendo esse o sentimento proposto pelo compositor. Não se póe em questão ser essa análise subjetiva feita para os cinco primeiros compassos desse madrigal algo extremamente individual e que pode ser totalmente modificado pela percepção de outras pessoas. Mas encontramos também aqui um traço indelével da estética Maneirista, pois o subjetivismo e a personificação total do artista é transferida para seu interlocutor, estando nesse ato de troca de impressóes um dos pontos principais dessa arte. Também cumpre-nos notar a semelhança do enfoque da análise desta com a figura 4, que trazia um trecho do madrigal O Sonno, de Cipriano da Rore. 
A comparação entre esses dois exemplos enriquece nossa discussão quando se nota que, no exemplo de Rore referente ao que aqui foi chamado de Maneirismo inicial, a ideia abstrata do sono - ato de dormir - fora transmitida para o trecho musical proposto pelo compositor. O mesmo ocorre na figura 6 com o excerto retirado do madrigal de Marenzio. Porém, identifica-se nesse último caso que além de retratar algo abstrato, o compositor trabalha com uma imagem subjetiva, que poderia denotar ambientes diferentes. Mas sua música se presta também a sugerir uma sensação ao seu ouvinte, direcionando-o para o ambiente que o compositor escolheu. Ou seja, através desse raciocínio, comprova-se ser o mesmo mecanismo utilizado anteriormente, mas agora com maior abrangência.

Todos os elementos levantados e os exemplos trazidos por essa pesquisa até aqui, contribuem para ampliar o entendimento sobre esse importante segmento do repertório do século XVI. A aceitaçáo da música do Maneirismo e o natural desenvolvimento de sua compreensão tem por objetivo permitir um maior aproveitamento dessa estética, no mínimo, bela. Porém, no seguir desse estudo encontramos o que pode ser considerado o auge da escrita musical do Maneirismo, e ao mesmo tempo, o ponto final da estética - a obra do compositor italiano Carlo Gesualdo. Nenhuma outra personagem do período foi tão maneirista como Gesualdo, e exatamente por esse motivo sua obra extrapola os limites do inteligível. Sendo que é impossível tratar desse assunto sem incluir a obra desse compositor, mesmo ela contribuindo mais para confundir do que para contribuir com o nosso entendimento.

Gesualdo era membro de uma poderosa nobre família no reino de Nápoles e muito jovem foi alçado à categoria de príncipe. A importância política que foi obrigado a exercer, bem como suas tragédias pessoais, conferem à sua biografia traços de sua própria estética. Seus dramas amorosos, aliados a uma fé inabalável e por vezes doentia, transformaram a vida de Gesualdo em um enredo próprio do Maneirismo artístico. Nos seis livros de madrigais italianos publicados por ele entre os anos de 1594 e 1613, ano de sua morte, encontramos o testamento musical dessa estética, repleto de excessos e excentricidades, como sempre apontou a escrita maneirista.

A ligação entre a obra de Gesualdo e o Maneirismo é conhecida da literatura especializada a muito tempo, antes mesmo da música que hoje atribuímos ao Maneirismo ser mais bem reconhecida e entendida efetivamente como tal. Glenn Watkins em seu livro Gesualdo - The Man and his Music (Oxford University Press, 1991) diz que a obra de Gesualdo é considerada a expressão máxima do Maneirismo, e atribui isso ao fato de exemplificar musicalmente todas as principais características aceitas sobre a estética. Amplia ainda a reflexão dizendo que o "mundo torturante" que o compositor traz para seus madrigais, é o que há de mais maneirista (WATKINS, 1991, p. 106).

Outra citação intrigante e reveladora sobre esse fato nos dá Don Harran em seu artigo "Mannerism" in the Cinquecento Madrigal?(1969, The Musical Quartely, Volume LV, Issue 4, p. 521-544).

A história do madrigal é, de certo modo, uma descrição da luta dos compositores para encontrar um equilíbrio entre as exigências incompatíveis entre polifonia e homofonia; o cromatismo e escrita diatônica; versos literais e abstratos. Eles confiavam na poesia para trazer a lei e a ordem para uma situaçáo que, em sua forma extrema, só poderia levar à anarquia musical. Essa ordem e essa lei eram mais aparente do que real, e não puderam afastar o fim do madrigal, 
seu romper por conflitos musicais fundamentais demais para serem contidos por meios poéticos - não foi isso que aconteceu com Gesualdo? ${ }^{4}$ (p. 538)

A coincidência do título do artigo trazer uma interrogação e o trecho aqui escolhido também, nos diz muito sobre como o autor lidou com esse assunto. Após anos tratando desse tema, Harran se mantinha cético sobre o quanto suas pesquisas e de seus contemporâneos (década de sessenta e setenta do século XX) haviam avançado. Mas o que mais nos interessa é sua descrição da música maneirista ser elaborada através de conceitos musicais inconciliáveis. E ter sido nesse excesso de paradoxismo que o estilo se inviabilizou. Estando Gesualdo no auge do processo, e tendo o levado ao limite, sua obra marca o fim da expressão. Não sem nos deixar como legado a essência da escrita maneirista.

Muitos seriam os exemplos dentro da obra do compositor que poderiam nos auxiliar nesse entendimento. Mas iremos nos concentrar no madrigal Io Parto do sexto livro de madrigais, e extrair dele as principais informaçóes que enriquecerão esse trabalho.

A própria origem deste poema nos coloca uma situação, no mínimo, pouco usual, pois é consenso entre os estudiosos dedicados à obra de Gesualdo que os textos dos madrigais de seus últimos dois livros foram escritos pelo próprio compositor (XXX). Não obstante a todas as reflexóes que este fato pode nos ensejar, ele representa antes de tudo o alto nível intelectual do compositor, o que por si só, já nos aproxima do ambiente elitista e sofisticado do maneirismo artístico. Neste texto, encontramos revelaçóes pelo que ele nos mostra e também pelas características que não nos apresenta.

"Io parto" e non più dissi,

Che il dolore privò di vita il core.

Allor proruppe in pianto e disse Clori

Con interotti omèi: "Dunque ai dolori

Io resto. Ah, non fia mai

Ch'io non languisca, in dolorosi lai."

Morto fui, vivo son, che i spirti spenti

Tornaro in vita a sì pietosi accenti. ${ }^{5}$

Temos representado no poema as características comumente identificadas no gênero poético do madrigal do século XVI: o texto de curta extensão; a manutenção do esquema livre de frases em setenário (sete sílabas poéticas) e hendecassílabos (onze sílabas poéticas); o afastamento do estilo do "Petrarquismo", cuja característica principal seriam as imagens grandiosas com alusóes à natureza, substituído por um poema amoroso mais subjetivo e introspectivo (HARRÁN,1988, p. 106).

$4 \quad$ A history of the madrigal reads, in a sense, as a description of the struggle of composers to strike a balance between the antithetical demands of polyphony and homophony, chromaticism and diatonicism, literal and abstract verse-settings. They relied on poetry to bring law and order into a situation which, in its extreme form, could only lead to musical anarchy. That this law and order was more apparrent than real, that it could not ward off the final downfall of the madrigal, its bursting asunder through musical conflicts too fundamental to be contained by poetic means - is this not what happened with Gesualdo?

5 "Eu parto" e não mais disse/ Que a dor privou de vida meu coração/ Então, rompe-se em lágrimas e diz Clori aos soluços: "Apesar das dores. Eu fico"/ Ah, que eu não definha em dolorosos ais/ Morto fui, vivo estou, qual espíritos extintos/ Tornaram a viver com piedosos acentos". 
Não menos importante é a ausência de elementos que na ocasião se colocavam de forma quase inerente à escrita madrigalesca, como as imagens poéticas mais sensuais e provocativas. Termos como "boca", "beijo", "olhos", tão comuns na produção madrigalesca, até mesmo do próprio Gesualdo em suas fases anteriores, aqui são completamente desprezados. No lugar deles encontramos uma narração amorosa baseada na ideia da dor e da finitude, seja do amor ou mesmo da vida. Estes elementos são a síntese da poesia maneirista.

Mas é no elemento mais subjetivo desta análise que encontramos o fator de maior relevância para a investigação, a descontinuidade com que o texto nos é apresentado. Conforme já havia sido observado pelo autor Daniel B. Rowland, em seu livro Mannerism - Style and Mood, o poema característico do maneirismo não é elaborado através de uma ideia fluida e lógica, mas sim de um fluxo descontínuo e confuso. Segundo ele, "é mais uma sequência de palavras que uma unidade de pensamento" ${ }^{6}$ (1964, p.30). Em qualquer um dos versos do poema de Io Parto que nos concentremos, encontraremos uma escrita aos solavancos, como se as palavras fossem ditas de forma descontínua, aos soluços. Tomemos, por exemplo, o ápice dramático da narração quando o texto traz:

Morto fui, vivo son, che i spirti spenti

A própria colocação das vírgulas, feita pelo compositor, colabora com a sensação de sentenças fortes, com ideias abruptas e proferidas de maneira descontínua. E na elaboração musical proposta, esta característica é ressaltada pela alteração que se dá na escrita dentro da frase musical.

Figura 7: Madrigal Io Parto - c. 28 a 33

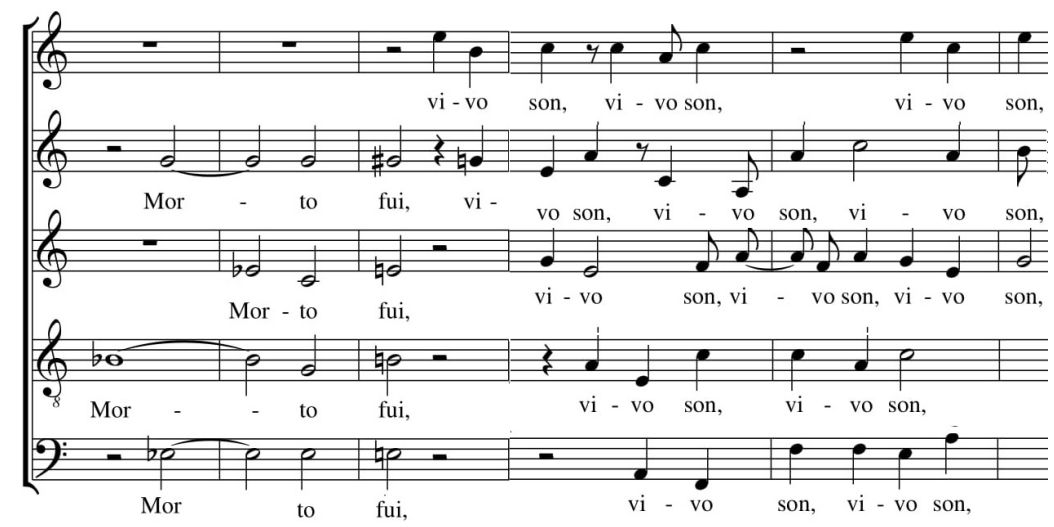

Fonte - Elaborado pelo autor

Tamanha é a abrangência deste aspecto, que Gesualdo o emprega na música mesmo quando o texto não está totalmente segmentado. Nota-se isto na segunda frase do poema - Che il dolore privò di vita il core - cuja elaboração musical acaba por seccioná-la além do que a narração propóe, ao incluir uma pausa geral no meio da frase:

6 "...it is more a string of words than a unit of thought" 
Figura 8: Madrigal Io Parto - c. 6 a 12

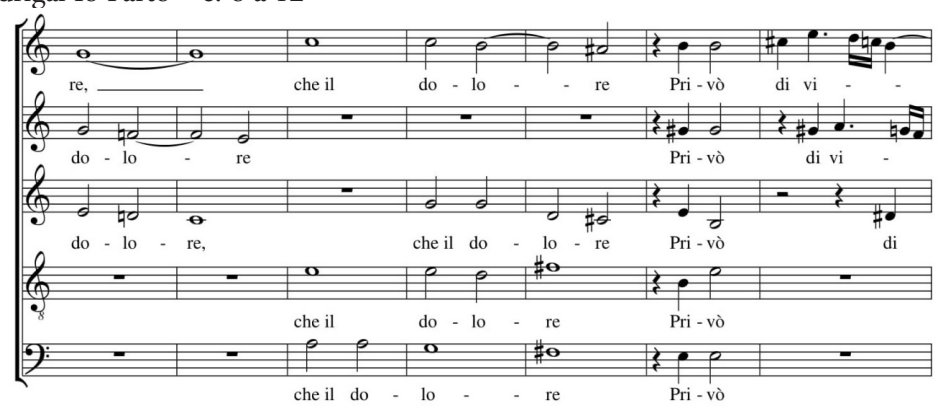

Fonte - Elaborado pelo autor

Destaca-se que ao longo de todo o madrigal, que contém 45 compassos, o que caracteriza um tamanho normal para o período, encontramos exatamente 10 momentos iguais ao retratado pelo exemplo 2. Ou seja, ao longo deste poema de apenas oito versos, o compositor por 10 vezes elaborou pausas gerais como a exemplificada na figura anterior. Destas constataçóes depreende-se ser a escrita poética de Io Parto uma narração descontínua, o que se encaixaria na ideia de uma narração amorosa feita através de um labirinto de termos e sentenças.

Por fim, temos a questão central da escrita deste madrigal, e de quase toda a obra de Carlo Gesualdo, que melhor se insere na estética maneirista - sua condução harmônica. Definir de forma categórica em qual momento da transição modal/tonal esta escrita melhor se encaixa torna-se uma tarefa muito complexa, visto que temos tantos elementos que caracterizam a escrita modal como outros que sugerem um pensamento já tonal, mas ambas as visóes não são sólidas o suficiente para servir como uma nomenclatura definitiva. Foi em uma justa tentativa de esquematizar esta escrita que o autor Edward Lowinsky a definiu como "harmonia do século XVI", ou "atonalismo triádico" (1961). O que temos, de fato, é uma escrita harmônica sofisticada e complexa em que o compositor consciente dos caminhos esperados da escrita cuida por subvertê-los, não permitindo sensaçóes de repouso pleno ou de obtenção do objetivo sonoro (MCCLARY, 2004, p. 149).

Figura 9: Madrigal Io Parto - c. 1 a 6

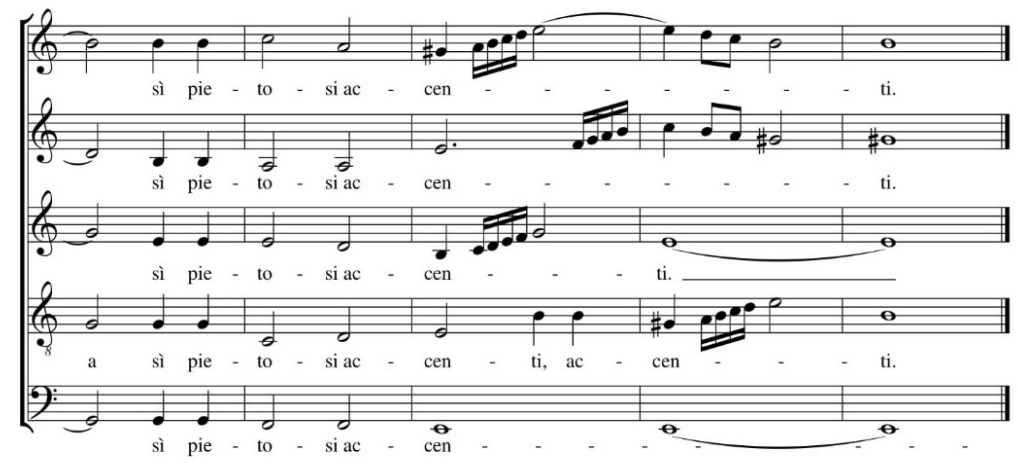

Fonte - Elaborado pelo autor 
Conforme representado no exemplo 4, apenas nos primeiros seis compassos da obra, tendo a voz do superius (sopranos) em pausa, já temos uma amostra de como a sensação de centro tonal será trabalhada ao longo da obra. A narração poética, que traz um discurso indireto, inicia-se com uma tríade maior sobre a nota $\mathrm{Mi}$, e após uma pausa geral, transforma-se em uma sequência de Ré menor/Si maior/Mi menor/Si maior. Não seria impossível traçarmos conjecturas sobre as relaçóes entre estas tríades, em especial a relação de quinta que se estabelece entre as notas $\mathrm{Si}$ e $\mathrm{Mi}$, mas esta tarefa seria pouco eficiente, visto que a relação entre as tríades é muito tênue, especialmente quando inserida nas frases subsequentes. $\mathrm{O}$ que temos é justamente o uso feito pelo compositor da falta de relações, ou da subversão delas, como elemento retórico.

Também revelador é o compositor percorrer toda a obra com elementos musicais que mesclam as duas últimas características levantadas por este estudo, porém conclui-lo com uma tríade sobre a nota $\mathrm{Mi}$, mantendo assim a coerência com o início da obra.

Figura 10: Madrigal Io Parto - c. 41 a 45

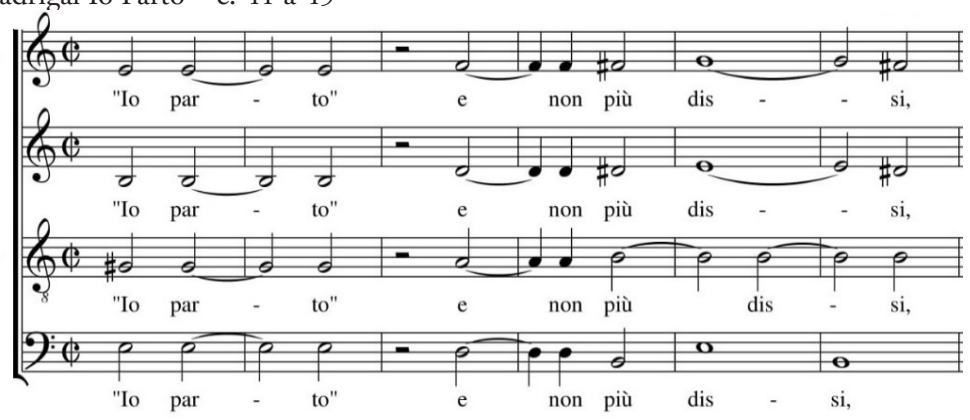

Fonte - Elaborado pelo autor

Ou seja, o compositor inicia sua obra propondo um caminho harmônico baseado na tradição do período e ao final da mesma não se furta de entregar o resultado esperado. Porém, ao longo de toda a narração amorosa que seu texto propóe, este caminho é constantemente deturpado, como forma de chamar a atenção dos ouvintes através de efeitos musicais inusitados. Assim, Gesualdo confirma sua total inserção na estética do Maneirismo utilizando as ferramentas retóricas mais aprofundadas e sofisticadas que tinha a sua disposição para criar um ambiente torturante e dramático que fizesse jus à sua narração poética. 


\section{Conclusão}

A partir dos elementos levantados e discutidos nesse trabalho algumas conclusōes são possíveis. A primeira delas é quanto a pertinência do Maneirismo enquanto reclassificação estética da arte do final do período do Renascimento, sem a qual o catálogo artístico daquelas décadas será entendido de forma insuficiente. A segunda conclusão é a comprovação da existência de uma vertente maneirista no repertório musical e de como sua identificação se faz condição necessária para o entendimento deste repertório. E por último, e mais importante, a constatação de que a arte do Maneirismo continua sendo uma linguagem estética pouco entendida que ainda carece de pesquisas e entendimentos, especialmente em sua vertente musical. 


\section{Referências}

ATLAS, Allan W. Renaissance Music, Music in Western Europe, 1400 - 1600. New York: W.W. Norton \& Company, 1998.

BESSELER, Heinrich. Bourdon und Fauxbourdon. Leipizig: Breitkopf \& Hãrtel, 1950.

BROWN, M. Howard. Music in the Renaissance. New Jersey: Prentice-Hall, 1976.

EINSTEIN, Alfred. The Italian Madrigal. New Jersey: Princeton University Press, 1971.

FREEDBERG, Sydney Joseph. Parmigianino - his works in panting. Greenwold Press, 1971.

GONZALES, M. M. Arnold Hauser e a Literatura Espanhola. Pandaemonium Germanicum, 16/2010.2, p.122-137. 2010.

HARRÁN, Don. "Maniera” E Il Madrigale: Una raccolta di Poesie Musicali del Cinquecento. Firenze: Leo S. Olschki Editore, 1969.

HAUSER, Arnold. Maneirismo: a crise da Renascença e a origem da arte moderna. Tradução de Magda França. São Paulo: Editora da Universidade de São Paulo, 1965.

HOCKE, Gustav R. Maneirismo na Literatura. Tradução Fernando de Moraes Barros. São Paulo:Perspectiva, 2005.

HOCKE, Gustav R. Maneirismo: o mundo como labirinto. Tradução Clemente Raphael Mahl. São Paulo:Perspectiva, 1974.

LOWINSKY, Edward E. Tonality and Atonality in Sixteenth-Century Music. colaborador Stravinsky, California: University of California Press, 1961.

MANGANI, Marco. Le Strutture Tonali Della Polifonia: Appunti Sulla Riflessione Novecentesca e Sul Dibattito Attuale. In: GARGIULO, Piero. MANGANI, Marco (Org.) Le Strutture Tonali nei Repertori Polifonici.Lucca: Libreria Musicale Italiana, 2004/1.

MANN, Nicholas. Renaissance. Londres: Andromeda Oxford Limited, 2004.

McCLARY, Suzan. Modal Subjectivities - self-fashioning in the Italian Madrigal. California: University of California Press, 2004.

ROWLAND, Daniel B. Mannerism - Style and Mood. New Haven and London: Yale University Press, 1964.

SHEARMAN, John. O Maneirismo. Tradução de Octávio Mendes Cajado. São Paulo: Cultrix, Ed. Da Universidade de São Paulo, 1978.

TERPENING, Ronnie H. Lodovico Dolce, Renaissance Man of Letters. Toronto: University os Toronto Press Incorporated, 1997.

WATKINS, Glenn. GESUALDO The Man and His Music. 2 Ed. Oxford: Claredon Press, 1991. 